\title{
Chronic widespread pain in spondyloarthritis
}

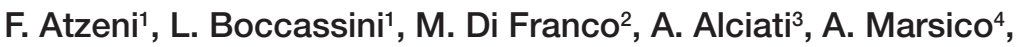 \\ M. Cazzola ${ }^{5}$, G. Cassisi ${ }^{6}$, P. Sarzi-Puttini ${ }^{1}$ \\ ${ }^{1}$ Rheumatology Unit, L. Sacco University Hospital, Milan; \\ ${ }^{2}$ Rheumatology Unit, Department of Internal Medicine and Medical Specialties, La Sapienza University, Rome; \\ ${ }^{3}$ Hermanas Hospitalarias, FoRiPsi, Department of Clinic Neurosciences, Villa San Benedetto Menni, \\ Albese con Cassano (CO); ${ }^{4}$ Reumatology Unit, S.S. Annunziata Hospital, Taranto; \\ ${ }^{5}$ Rehabilitation Unit, Busto Arsizio Ospedale di Circolo, Presidio Ospedaliero di Saronno (VA); \\ ${ }^{6}$ Rheumatology Branch, Specialist Outpatients Department, Belluno, Italy
}

\section{SUMMARY}

The pain associated with spondyloarthritis (SpA) can be intense, persistent and disabling. It frequently has a multifactorial, simultaneously central and peripheral origin, and may be due to currently active inflammation, or joint damage and tissue destruction arising from a previous inflammatory condition. Inflammatory pain symptoms can be reduced by non-steroidal anti-inflammatory drugs, but many patients continue to experience moderate pain due to alterations in the mechanisms that regulate central pain, as in the case of the chronic widespread pain (CWP) that characterises fibromyalgia (FM). The importance of distinguishing SpA and FM is underlined by the fact that SpA is currently treated with costly drugs such as tumour necrosis factor (TNF) inhibitors, and direct costs are higher in patients with concomitant CWP or FM than in those with FM or SpA alone. Optimal treatment needs to take into account symptoms such as fatigue, mood, sleep, and the overall quality of life, and is based on the use of tricyclic antidepressants or selective serotonin reuptake inhibitors such as fluoxetine, rather than adjustments in the dose of anti-TNF agents or disease-modifying drugs.

Key words: Spondyloarthritis, Fibromyalgia, Prevalence, Disease activity, Ankylosing spondylitis disease activity score, Bath ankylosing spondylitis disease activity index.

Reumatismo, 2014; 66 (1): 28-32

\section{INTRODUCTION}

pondyloarthritis $(\mathrm{SpA})$ refers to a fam$\checkmark$ ily of diseases with a number of common clinical features (1). The most distinguishing are axial joint inflammation, asymmetric oligoarthritis, dactylitis and enthesitis, but others include genital and skin lesions, eye and bowel involvement, an association with current or previous infection, and a close correlation with human leukocyte antigen (HLA) B27 (2, 3).

The pain associated with SpA can be intense, persistent and disabling $(4,5)$. It frequently has a multifactorial, simultaneously central and peripheral origin (6), and may be due to currently active inflammation, or joint damage and tissue destruction arising from a previous inflammatory condition (7). Inflammatory pain symptoms can be reduced by non-steroidal anti- inflammatory drugs (NSAIDs), but many patients continue to experience moderate pain $(8,9)$ due to alterations in the mechanisms that regulate central pain, as in the case of the chronic widespread pain (CWP) that characterises fibromyalgia (FM) (10). The many complex mechanisms giving rise to CWP include temporal summation (wind-up), long-term potentiation (LTP), heterosynaptic potentiation, dysfunctional descending pain inhibition, and activation of the descending facilitatory pathway (11). Experimental studies of sensitivity to pain have shown that the pressure eliciting pain (also known as the pressure pain threshold or PPT) is lower in patients with rheumatoid arthritis (RA) than in healthy controls (6). The fact that this true at articular and non-articular sites suggests that the widespread pain associated with RA is mediated by changes in the mechanisms regulating 
central pain, such as central sensitisation and a lack of conditioned pain modulation. Incel et al. studied 17 Ankylosing Spondylitis (AS) patients, 20 RA patients, and 21 healthy volunteers, and found that the PPTs of the RA patients (but not those with AS) were significantly lower than the PPTs of healthy volunteers (12). However, other studies have shown that widespread pain conditions such as FM significantly increase AS disease activity. The growing evidence that there is an association between FM and SpA increases the need to distinguish their clinical features because the evaluation of SpA can be complicated by the presence of FM (13-16). The main cause of diagnostic confusion relating to the 1990 American College of Rheumatology (ACR) criteria (17) is the overlap of enthesitis in $\mathrm{SpA}$ with the tender points (TPs) of FM. TP counts were therefore replaced by patient self-assessment in the 2010 ACR diagnostic criteria for FM (18), but this has has not necessarily made them any less confusing (19). The two conditions have many similarities. SpA is diagnosed on the basis of the presence of inflammatory chronic back pain and morning stiffness $(20,21)$, but these are often encountered in FM patients. Furthermore, the typical characteristics of FM (fatigue, depression, anxiety and sleep disturbances) (22) are also significant aspects of AS, and are closely associated with pain, particularly in women (21). Such similarities not only lead to diagnostic problems, but may also make it more difficult to interpret treatment failure or disease relapse (23). Consequently, it has been suggested that SpA and FM can best be differentiated by means of the power Doppler ultrasound (PDUS) investigation of enthesitis (24), although this is not universally available in everyday clinical practice $(25,26)$.

\section{THE IMPACT OF CWP ON DISEASE ACTIVITY INDICES}

Disease activity indices are often used in patients with $\operatorname{SpA}(27,28)$, and the good correlation between the presence of CWP or FM and the self-reported indices of AS (including the Bath Ankylosing Spondylitis Disease Activity Index, BASDAI) (29) suggests that the CWP frequently observed in women with inflammatory rheumatic diseases may also be frequent in women with axial SpA. This may cause diagnostic delays, and could provide a further explanation for the finding that, at any given level of radiographic damage, women's selfreported functional limitations are worse than those of men. As women with primary FM have much higher BASDAI scores than women with AS (23), BASDAI may not be a good means of assessing inflammatory disease activity in $\mathrm{SpA}$ patients.

Patients with concomitant AS and FM are more functionally impaired, and have higher BASDAI and Ankylosing Spondylitis Functional Index (BASFI) scores than those of patients with either disease alone (30). The prevalence of FM in one study of 71 patients with AS was $15 \%(45.5 \%$ males and $54.5 \%$ females), and these patients all had significantly higher BASDAI, BASFI and Ankylosing spondylitis quality of life (ASQoL) scores (31). Furthermore, a cross-sectional Spanish study of 462 patients with definite AS found that their BASDAI, BASFI and total Bath AS Radiology Index (BASRI) scores were all greatly affected by the presence of FM, which distorted the measures of disease activity and functional damage (32).

Another cross-sectional study has found that FM is also frequent in axial SpA, and once again more prevalent in female patients (33). Having can worsen the symptoms of disease activity, affect function, and compromise the quality of life: as the Ankylosing Spondylitis Disease Activity Score (ASDAS) includes markers of inflammation markers it may be more useful than BASDAI in clinical practice.

One study of 547 patients in the Scotland and Ireland Registry for Ankyolsing Spondylitis (SIRAS) (34) used four-view body manikins to obtain information concerning CWP not only on the basis of the 1990 ACR criteria for FM (ACR-CWP: i.e. chronic pain for $>3$ months in two contra- 
lateral body quadrants, plus axial pain), but also on the basis of an alternative definition (aCWP) that required chronic pain in two contralateral body quadrants, but excluded pain in the axial skeleton and/ or buttocks because it was felt that spinal disease would greatly affect the reporting and complicate the interpretation of the results. It was found that the age- and gender- adjusted prevalence of aCWP in AS was almost three times higher than in the general population, and was related to both individual and clinical factors (34).

\section{CWP AND PSORIATIC ARTHRITIS}

Psoriatic arthritis (PsA) is a chronic inflammatory arthropathy of unknown etiology whose various manifestations include mono-oligoarthritis (an erosive polyarthritis that indistinguishable from RA) and spondyloarthropathy with axial involvement or enthesitis, and affect up to one-third of psoriatic patients (35). Although the real prevalence of CWP in PsA patients is unclear, one study found tenderness in ten or more fibrotic sites in $24 \%$ of patients with PsA and $57 \%$ of RA patients (36). If there are no objective signs of entheseal inflammation, it can be difficult to distinguish enthesitic and CWP clinically, because the symptoms and signs may be aspecific. However, univariate analysis of a cross-sectional study of 266 patients with PsA and 120 with FM (37) showed that the latter had higher mean TPs and enthesitis scores, more somatic symptoms, and responded less to NSAIDs, and multivariate analysis showed that the presence of $\geq 6$ FM-associated symptoms and $\geq 8$ TPs was the best predictor of FM. The authors concluded that PsA and FM have some common clinical features, but that the number of FM-associated symptoms and the number of TPs were the most useful variables distinguishing FM.

As in the case of RA, the inflammation affecting different tissues in PsA patients can be detected and characterised early by means of ultrasonography, which is useful for the differential diagnosis.

\section{TREATMENT OF PATIENTS WITH SPA AND CONCOMITANT CWP}

Although challenging, it is important to identify CWP in SpA patients because it can have a considerable impact on their health-related quality of life, and is associated with high rates of use of healthcare resources (38-40). The difficulties in everyday living activities reported by patients with CWP or FM are as severe as those reported by patients with RA (41), and more severe than those reported by patients with osteoarthritis or other painful conditions $(42,43)$. The general level of well-being of FM patients referred to a specialist is lower than that of patients with AS, and they are also more expensive to treat (44). However, the direct costs of treating concomitant $\mathrm{SpA}$ (which is currently treated with costly tumour necrosis factor (TNF) inhibitors) and CWP or FM are higher than those of treating FM or SpA alone (45).

It is particularly important to recognise the presence of concomitant CWP in patients with chronic structural diseases in order to ensure their optimal management. AntiTNF drugs are ineffective in patients complaining of pain even when inflammation is effectively controlled, and this can lead to unnecessary changes in treatment or dose escalations.

Treating CWP in SpA patients is particularly challenging because little is known about its etiology and the patients respond poorly to conventional treatments: for example, NSAIDs alone have no effect on CWP caused by central sensitisation, and are probably unlikely to be effective in SpA patients $(8,9)$.

Controlled studies have shown that tricyclic antidepressants (e.g. amitriptyline), selective serotonin reuptake inhibitors (e.g. fluoxetine), and dual serotonin and norepinephrine inhibitors (e.g. venlafaxine, milnacipram and duloxetine) can relieve pain and improve the quality of life patients with FM $(46,47)$.

The most widely accepted and beneficial forms of non-pharmacological therapy seem to be physical exercise and multi- 
modal cognitive behavioural therapy (46, 47). However, as no single pain treatment is ideal, it is recommended to adopt an approach based on combined treatments.

\section{CONCLUSIONS}

Chronic widespread pain in SpA or PsA does not increase overall mortality but negatively affects the patients' quality of life, and its presence should be recognised by rheumatologists. Mechanism-based pain management should consider its simultaneous peripheral and central origin, including the effects of inputs from the brain and the descending inhibitory pathways, and optimal therapy should take into account symptoms such as fatigue, mood and disturbed sleep.

\section{REFERENCES}

1. Braun J, Sieper J. Ankylosing spondylitis. Lancet. 2007; 369: 1379-90.

2. Gladman DD. Clinical aspects of the spondyloarthropathies. Am J Med Sci. 1988; 3: 234-8.

3. Van Der Linden S, Van Der Heijde D. Ankylosing spondylitis: clinical features. Rheum Dis Clin North Am. 1998; 24: 663-76.

4. Kazis LE, Meenan RF, Anderson JJ. Pain in the rheumatic diseases. Investigation of a key health status component. Arthritis Rheum. 1983; 26: 1017-22.

5. Atzeni F, Cazzola M, Benucci M, Di Franco M, Salaffi F, Sarzi-Puttini P. Chronic widespread pain in the spectrum of rheumatological diseases. Best Pract Res Clin Rheumatol. 2011; 25: 165-71.

6. Dhondt W, Willaeys T, Verbruggen LA, Oostendorp RA, Duquet W. Pain threshold in patients with rheumatoid arthritis and effect of manual oscillations. Scand J Rheumatol. 1999; 28: 88-93.

7. Whittle SL, Colebatch AN, Buchbinder R, Edwards CJ, Adams K, Englbrecht M, et al. Multinational evidence-based recommendations for pain management by pharmacotherapy in inflammatory arthritis: integrating systematic literature research and expert opinion of a broad panel of rheumatologists in the $3 \mathrm{e}$ Initiative. Rheumatology (Oxford). 2012; 51: 1416-25.

8. Wolfe F, Michaud K. Assessment of pain in rheumatoid arthritis: minimal clinically significant difference, predictors, and the effect of anti-tumor necrosis factor therapy. J Rheumatol. 2007; 34: 1674-83.

9. Lee YC, Cui J, Lu B, Frits ML, Iannaccone CK, Shadick NA, et al. Pain persists in DAS28 rheumatoid arthritis remission but not in ACR/ EULAR remission: a longitudinal observational study. Arthritis Res Ther. 2011; 13: R83.

10. Phillips K, Clauw DJ. Central pain mechanisms in chronic pain states - maybe it is all in their head. Best Pract Res Clin Rheumatol. 2011; 25: 141-54.

11. Woolf CJ. Central sensitization: implications for the diagnosis and treatment of pain. Pain. 2010; 152: S2-15.

12. Incel NA, Erdem HR, Ozgocmen S, Catal SA, Yorgancioglu ZR. Pain pressure threshold values in ankylosing spondylitis. Rheumatol Int. 2002; 22: 148-50.

13. Konno T. Differentiation of the clinical features of psoriatic arthritis and fibromyalgia. J Rheumatol. 2012; 39: 11.

14. Fitzcharles MA, Boulos P. Inaccuracy in the diagnosis of fibromyalgia syndrome: analysis of referrals. Rheumatology. 2003; 42: 263-7.

15. Salaffi F, Sarzi-Puttini P, Ciapetti A, Atzeni F. Clinimetric evaluations of patients with chronic widespread pain. Best Pract Res Clin Rheumatol. 2011; 25: 249-70.

16. Salaffi F, Sarzi-Puttini P, Ciapetti A, Atzeni F. Assessment instruments for patients with fibromyalgia: properties, applications and interpretation. Clin Exp Rheumatol. 2009; 27: S92-105.

17. Wolfe F, Smythe HA, Yunus MB, Bennett RM, Bombardier C, Goldenberg DL, et al. The American College of Rheumatology 1990 criteria for the classification of fibromyalgia: report of the Multicenter Criteria Committee. Arthritis Rheum. 1990; 33: 160-72.

18. Wolfe F, Clauw DJ, Fitzcharles MA, Goldenberg DL, Katz RS, Mease P, et al. The American College of Rheumatology preliminary diagnostic criteria for fibromyalgia and measurement of symptom severity. Arthritis Care Res (Hoboken). 2010; 62: 600-10.

19. Salaffi F, Sarzi-Puttini P. Old and new criteria for the classification and diagnosis of fibromyalgia: comparison and evaluation. Clin Exp Rheumatol. 2012; 30: 3-9.

20. Sieper J. How to define remission in ankylosing spondylitis? Ann Rheum Dis. 2012; 71: i93-5.

21. Khan MA. Update on spondyloarthropathies. Ann Intern Med 2002; 136: 896-907.

22. Cazzola M, Sarzi-Puttini P, Stisi S, Di Franco M, Bazzichi L, Carignola L, et al. Fibromyalgia syndrome: definition and diagnostic aspects. Reumatismo. 2008; 60: 3-14.

23. Heikkila S, Ronni S, Kautiainen HJ, Kauppi MJ. Functional impairment in spondyloarthropathy and fibromyalgia. J Rheumatol. 2002; 29: 1415-9. 
24. Gutierrez M, Di Geso L, Salaffi F, Bertolazzi C, Tardella M, Filosa G, et al. Development of a preliminary US power Doppler composite score for monitoring treatment in PsA. Rheumatology (Oxford). 2012; 51: 1261-8.

25. Gutierrez M, Luccioli F, Salaffi F, Bartoloni E, Bertolazzi C, Bini V, et al. Ultrasound revealing subclinical enthesopathy at the greater trochanter level in patients with spondyloarthritis. Clin Rheumatol. 2012; 31: 463-8.

26. Gutierrez M, Filippucci E, Salaffi F, Di Geso L, Grassi W. Differential diagnosis between rheumatoid arthritis and psoriatic arthritis: the value of ultrasound findings at metacarpophalangeal joints level. Ann Rheum Dis. 2011; 70: 1111-4.

27. Coates LC, Mumtaz A, Helliwell PS, Mease PJ, Callis-Duffin K, Krueger GG, et al. Development of a disease severity and responder index for psoriatic arthritis (PsA) - report of the OMERACT 10 PsA special interest group. J Rheumatol. 2011; 38: 1496-501.

28. Sieper J, Rudwaleit M, Baraliakos X, Brandt J, Braun J, Burgos-Vargas R, et al. The Assessment of SpondyloArthritis international Society (ASAS) handbook: a guide to assess spondyloarthritis. Ann Rheum Dis. 2009; 68: ii1-44.

29. Slobodin G, Reyhan I, Avshovich N, BalbirGurman A, Boulman N, Elias M, et al. Recently diagnosed axial spondyloarthritis: gender differences and factors related to delay in diagnosis. Clin Rheumatol. 2011; 30: 1075-80.

30. Aloush V, Ablin JN, Reitblat T, Caspi D, Elkayam O. Fibromyalgia in women with ankylosing spondylitis. Rheumatol Int. 2007; 27: 865-8.

31. Azevedo VF, Paiva Edos S, Felippe LR, Moreira RA. Occurrence of fibromyalgia in patients with ankylosing spondylitis. Rev Bras Reumatol. 2010; 50: 646-50.

32. Almodóvar R, Carmona L, Zarco P, Collantes E, González C, Mulero J, et al. Fibromyalgia in patients with ankylosing spondylitis: prevalence and utility of the measures of activity, function and radiological damage. Clin Exp Rheumatol. 2010; 28: S33-9.

33. Salaffi F, De Angelis R, Carotti M, Gutierrez M, Sarzi-Puttini P, Atzeni F. Fibromyalgia in patients with axial spondyloarthritis: epidemiological profile and effect on measures of disease activity. Rheumatol Int. 2014. [Epub ahead of print].

34. Atzeni F, Beasly M, Dean L, Jones G, SarziPuttini P, Macfarlane G. Do patients with ankylosing spondylitis have an excess prevalence of chronic widespread pain? Results from the Scotland and Ireland Registry for Ankylosing Spondylitis (SIRAS) and the MUSICIAN study. [Abstract]. Arthritis Rheum. 2013; 65: 1536.

35. Atzeni F, Ventura D, Batticciotto A, Boccassini L, Sarzi-Puttini P. Interleukin 6 blockade: tocilizumab in psoriatic arthritis. J Rheumatol. 2012; 89: 97-9.

36. Buskila D, Langevitz P, Gladman DD, Urowitz S, Smythe HA. Patients with rheumatoid arthritis are more tender than those with psoriatic arthritis. J Rheumatol. 1992; 19: 1115-9.

37. Marchesoni A, Atzeni F, Spadaro A, Lubrano E, Provenzano G, Cauli A, et al. Identification of the clinical features distinguishing psoriatic arthritis and fibromyalgia. J Rheumatol. 2012; 39: 849-55.

38. Mas AJ, Carmona LM, Valverde M, Ribas B; the EPISER Study Group. Prevalence and impact of fibromyalgia on function and quality of life in individuals from the general population: results from a nationwide study in Spain. Clin Exp Rheumatol. 2008; 26: 519-26.

39. Hughes G, Martinez C, Myon E, Ta1 C, Wessely $\mathrm{S}$. The impact of a diagnosis of fibromyalgia on health care resource use by primary care patients in the UK: an observational study based on clinical practice. Arthritis Rheum. 2006; 54: 177-83.

40. Kivimäki M, Leino-Arjas P, Kaila-Kangas L, Virtanen M, Elovainio M, Puttonen S, et al. Increased sickness absence among employees with fibromyalgia. Ann Rheum Dis. 2007; 66: 65-9.

41. Ofluoglu D, Berker N, Güven Z, Canbulat N, Yilmaz IT, Kayhan O. Quality of life in patients with fibromyalgia syndrome and rheumatoid arthritis. Clin Rheumatol. 2005; 24: 490-2.

42. Hawley DJ, Wolfe F. Pain, disability, and pain/ disability relationships in seven rheumatic disorders: a study of 1,522 patients. J Rheumatol. 1991; 18: 1552-7.

43. Verbunt JA, Pernot DHFM, Smeets RJEM. Disability and quality of life in patients with fibromyalgia. Health Qual Life Outcomes. 2008; 6: 8 .

44. Perrot S, Schaefer C, Knight T, Hufstader M, Chandran AB, Zlateva G. Societal and individual burden of illness among fibromyalgia patients in France: association between disease severity and OMERACT core domains. BMC Musculoskeletal Dis. 2012; 13: 22.

45. Aydin SZ, Can M, Atagunduz P, Direskeneli H. Active disease requiring TNF-alpha antagonist therapy can be well discriminated with different ASDAS sets: a prospective, follow-up of disease activity assessment in ankylosing spondylitis. Clin Exp Rheumatol. 2010; 28: 752-5.

46. Sarzi-Puttini P, Buskila D, Carrabba M, Doria A, Atzeni F. Treatment strategy in fibromyalgia syndrome: where are we now? Semin Arthritis Rheum. 2008; 37: 353-65.

47. Sarzi-Puttini P, Atzeni F, Salaffi F, Cazzola M, Benucci M, Mease PJ. Multidisciplinary approach to fibromyalgia: what is the teaching? Best Pract Res Clin Rheumatol. 2011; 25: 311-9. 